Results Intraoperative hemodynamics was statistically significantly more stable in SA group. In SA group bloody tap occurred once. While in GA group, two patients had hypoxia. The intra-operative complications were statistically non-significant between both groups. Post-operative complications were statistically significantly lower in SA group compared to GA group $(\mathrm{p}<0.05)$. Postoperative heart rate $(\mathrm{HR})$ was statistically significantly lower in the SA group compared to the GA group $(\mathrm{p}<0.05)$.

Conclusions Spinal anesthesia is a good alternative to general anesthesia in neonates for infraumbilical surgeries.

\section{PEDIATRIC ULTRASOUND-GUIDED DORSAL PENILE NERVE BLOCK PLUS SEDATION IN SPONTANEOUS BREATHING. A RETROSPECTIVE OBSERVATIONAL STUDY, PRELIMINARY RESULTS}

${ }^{1} \mathrm{~F}$ Meroi*, 'B Dottore, ${ }^{1} \mathrm{M}$ Comuzzi, ${ }^{2} \mathrm{~S}$ Intini, ${ }^{1} \mathrm{~L}$ Vetrugno, ${ }^{1} \mathrm{~T}$ Bove. ${ }^{1}$ University Hospital of Udine - Anesthesia and Intensive Care Department, Udine, Italy; ${ }^{2}$ University Hospital of Udine - General Surgery Unit, Udine, Italy

\subsection{6/rapm-2021-ESRA.129}

Background and Aims One of the most frequent surgical procedures in the pediatric population is circumcision-following which postoperative pain could be stressful. Usually, the most common approach is combining regional anesthesia techniques such as landmark dorsal penile nerve block (DPNB) with general anesthesia (GA). The hypothesis of this study investigates ultrasound-guided DPNB plus sedation in spontaneous breathing.

Methods Our ethical committee approved this study Prot. \#5848. 58 children who underwent circumcision at our University-Hospital between January 2016 and December 2019 were included: 35 received GA plus DPNB performed by the surgeon with a landmark technique; 23 were sedated in spontaneous breathing and the anesthetist performed an ultrasound-guided DPNB with the probe positioned transversally at the base of the penis - in-plane - to visualize the local anesthetic spread. The statistical analysis was achieved with commercially available software (MedCalc version 19.0.7, bvba, Ostend, Belgium).

Results Age, weight, and height were comparable between the two groups. Children who received ultrasound-guided DPNB had a statistically significant lower time to discharge from the operating room with faster awakening, lower pain levels immediately after surgery, less intraoperative opioid consumption with a lower rate of complications after 72 hours.

\begin{tabular}{|c|c|c|c|c|c|}
\hline & \multicolumn{2}{|c|}{ Landmark (35) } & \multicolumn{2}{|c|}{ Ultrasound-guided (23) } & $\begin{array}{c}\text { Mann - Whitney } \\
\text { pValue }\end{array}$ \\
\hline & Median & $\left(25^{\circ}-75^{\circ}\right)$ & Median & $\left(25^{\circ}-75^{\circ}\right)$ & \multirow{3}{*}{$\mathrm{p}<0.01$} \\
\hline $\begin{array}{c}\text { Opioid dose } \\
(\mu g / K g)\end{array}$ & 2.08 & $\begin{array}{c}(1.72- \\
2.38)\end{array}$ & 1.2 & $(0.96-1.61)$ & \\
\hline $\begin{array}{l}\text { Time to } \\
\text { discharge } \\
\text { (min) }\end{array}$ & 20 & $(15-27)$ & 4 & $(2-6)$ & \\
\hline
\end{tabular}
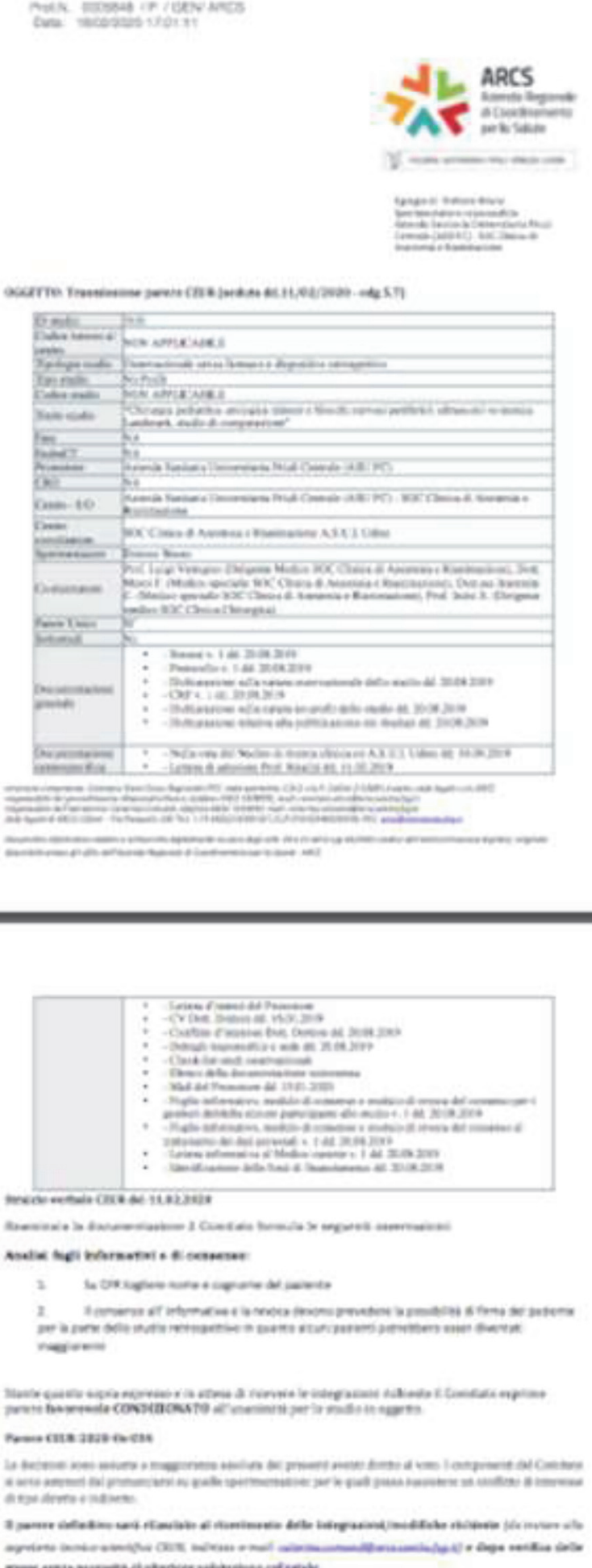

>nicis

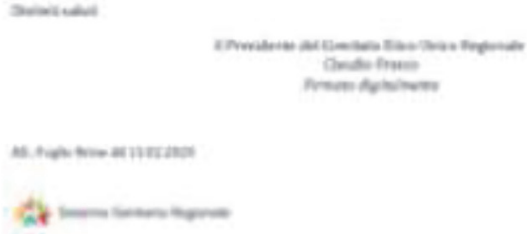

Abstract 129 Figure 1 


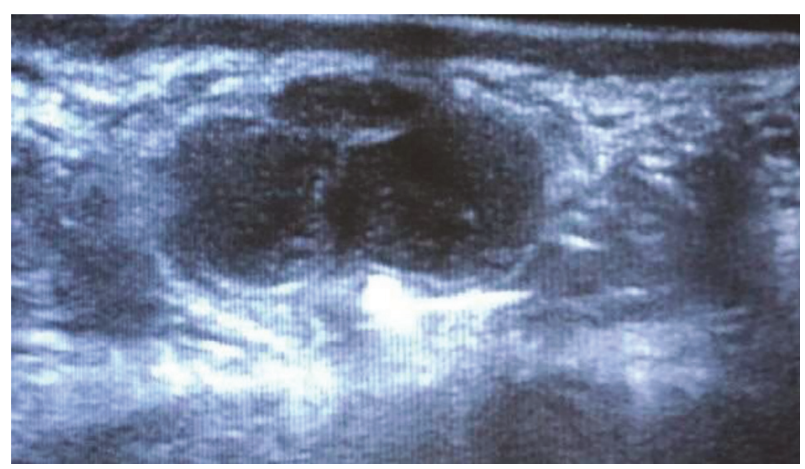

Abstract 129 Figure 2

Conclusions The ultrasound-guided DPNB associated with sedation and spontaneous breathing is a safe and effective strategy for the management of intra- and postoperative pain in children.

\section{COMPARISON OF INTRAPERITONEAL INSTILLATION OF MAGNESIUM SULPHATE AND BUPIVACAINE VERSUS INTRAVENOUS ANALGESIA IN LAPAROSCOPIC SURGERIES IN PEDIATRICS}

I Ahmed Walash*, W Sultan. Menofia University Hospitals, Shebin el-kom, Egypt

\subsection{6/rapm-2021-ESRA.130}

Background and Aims Administration of magnesium sulphate via different routes has been used in anaesthetic practice for decreasing perioperative pain. It is $\mathrm{N}$-methyl d-aspartate (NMDA) receptor antagonist and suppresses these receptor induced inflammation and hyper responsiveness. The antinociceptive effect of magnesium sulphate is not only useful in chronic pain, but it also determines in part, the duration and intensity of postoperative pain. These effects are due to calcium antagonism and decrease influx of calcium into the cell and antagonism of NMDA receptor. As these receptors regulate neuronal signalling and are involved in pain processing, magnesium sulphate by blocking this receptor, decreases postoperative pain as well.

Aim of the work studying analgesic efficacy of intraperitoneal instillation of a combination of Magnesium sulphate with bupivacaine versus ordinary parentral analgesics for pain relief after laparoscopic surgeries in pediatrics.

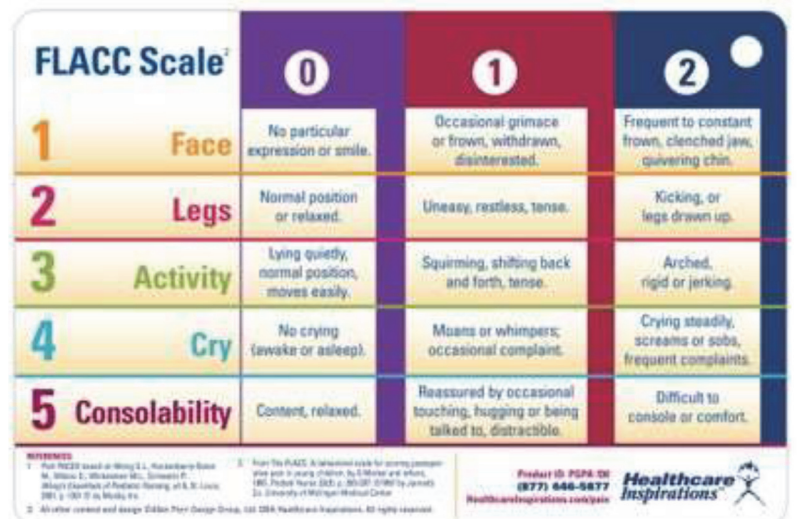

Abstract 130 Figure 1
Methods Groups: Group1: will receive ordinary analgesics via intravenous route as paracetamol $(7.5-10 \mathrm{mg} / \mathrm{kg})$ and ketorolac $(0.5 \mathrm{mg} / \mathrm{kg})$.

Group2: will receive (Magnesium sulphate $40 \mathrm{mg} / \mathrm{kg}$ and bupivacaine $4 \mathrm{mg} / \mathrm{kg}$ ) in $30 \mathrm{ml}$ of isotonic $0.9 \%$ N.S intra peritoneal at the end of surgery. Patient evaluated regarding FLACC score.

Results statistically significant difference according to FLACC.

highly statistically significant difference between the groups according to time to first analgesic administration.

and total analgesic requirement in the first $24 \mathrm{~h}$ postoperative.

Conclusions The intraperitoneal administration of combination of magnesium sulphate and bupivacaine is a safe and effective method in the management of postoperative pain after laparoscopic surgeries more than intravenous administration of ordinary analgesics in laparoscopic surgeries in pediatrics.

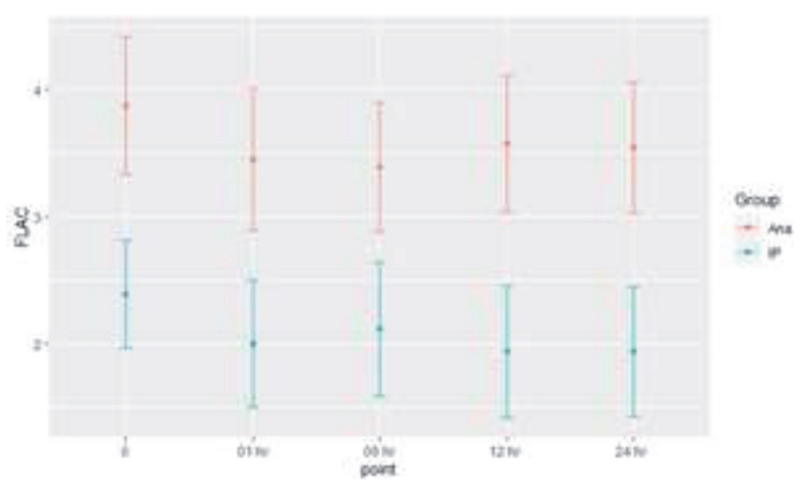

Abstract 130 Figure 2

Abstract 130 Table 1

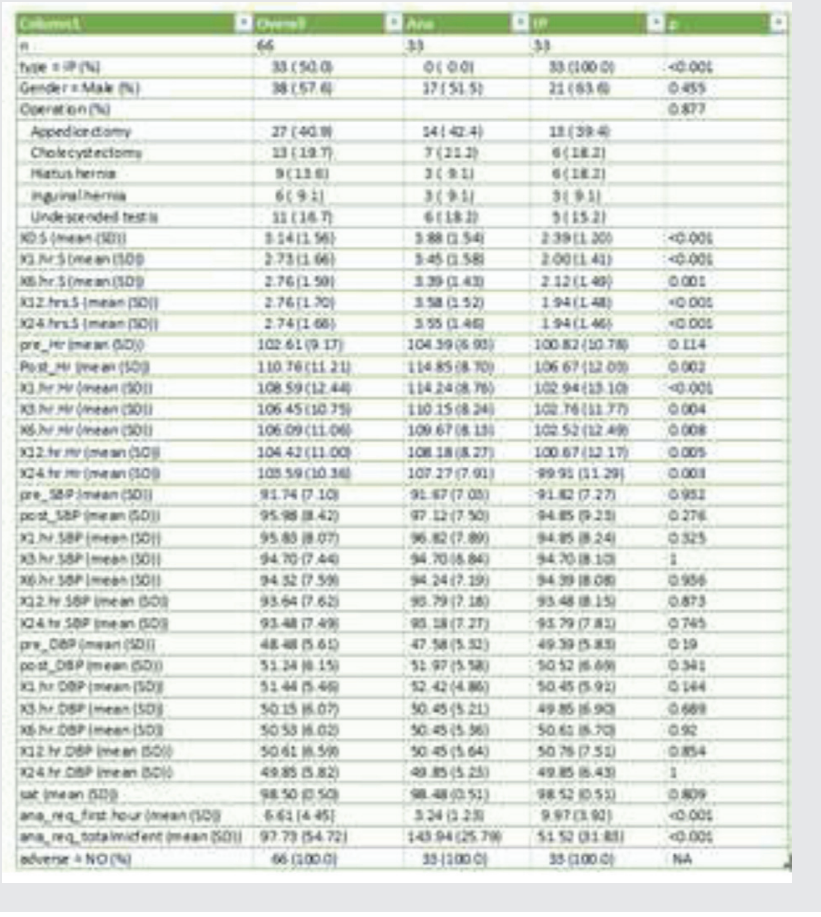

